\title{
Preliminary study on the detection of hepatitis E virus (HEV) antibodies in pigs and wild boars in Poland
}

\author{
Marcin Weiner ${ }^{1,3}$, Małgorzata Tokarska-Rodak ${ }^{1}$, Dorota Plewik ${ }^{2}$, Anna Pańczuk ${ }^{1}$, \\ Adam Szepeluk ${ }^{2}$, Monika Krajewska ${ }^{3}$ \\ ${ }^{1}$ Department of Health, ${ }^{2}$ Innovation Research Centre, \\ Pope John Paul II State School of Higher Education in Biala Podlaska, 21-500 Biala Podlaska, Poland \\ ${ }^{3}$ Department of Microbiology, National Veterinary Research Institute, 24-100 Pulawy, Poland \\ m.weiner@dydaktyka.pswbp.pl
}

Received: August 2, $2016 \quad$ Accepted: November 16, 2016

\begin{abstract}
Introduction: Although HEV infection in pigs does not pose a major economic risk to pork production, the risk of zoonotic transmission to humans is an important aspect of public health. HEV genotype 3 infections were reported in developed countries in individuals who had consumed raw meat or meat products from deer, wild boars, or pigs. The aim of the study was the analysis of the occurrence of HEV-specific antibodies among wild boars and domestic pigs in Poland. Material and Methods: A total of 290 samples from wild boars and 143 samples from pigs were tested. The antibodies were tested by ELISA. Results: The presence of anti-HEV IgG was demonstrated in $44.1 \%$ of pigs and $31.0 \%$ of wild boars. Anti-HEV IgG antibodies were detected in $1.4 \%$ of samples from pigs and in $2.1 \%$ of samples from wild boars at borderline level. The statistical analysis shows significant differences in the positive results for anti-HEV IgG between the groups of pigs and wild boars $(\mathrm{P}=0.0263)$. Conclusion: Regular surveillance of the occurrence of HEV in swine and wild boars should be performed in the future.
\end{abstract}

Keywords: wild boars, pigs, hepatitis E virus, antibodies, Poland.

\section{Introduction}

Hepatitis E virus (HEV), the aetiological agent of hepatitis E, is a member of the Orthohepesvirus genus within the Hepeviridae family and consists of genotypes 1,2,3, and 4 which infect humans and other mammals $(1,11,20,23)$. It is a non-enveloped virus, 27-34 nm in diameter, whose genome contains a nonsegmented positive-sense RNA chain $(10,23)$. HEV is the best known among the hepatitis viruses (HAV, $\mathrm{HBV}, \mathrm{HCV}$, and HDV) with an animal reservoir (13). Genotypes 1 and 2 of HEV have been found only in humans. In the developing countries of Asia, the Middle East, and Africa, HEV infection is endemic. In developed countries, HEV infections have only been diagnosed in individuals who have travelled to highly endemic areas. It is estimated that each year HEV cases are diagnosed in three million people worldwide (1). HEV genotypes 3 and 4 circulate in animals and humans and they are autochthonous in several industrialised countries of Europe, North America, and in Japan (10). Domestic pigs and wild boars are the main animal reservoir of these genotypes $(15,18,23)$, but $\mathrm{HEV}$ antibodies have been detected in many other animal species: rats, cats, monkeys, dogs, cattle, sheep, goats, mongooses, rabbits, chickens, ferrets, bats, and deer $(11,16,22,24)$.

HEV prevalence in pig herds in Europe ranges from $32 \%$ to $52 \%$. Seroprevalence does not depend on the age of the animal (7). Pigs can be infected through direct contact with infected animals, or via feed and water contaminated with faeces. The basic reproduction ratio $\left(R_{0}\right)$ is 8.8 , which means that one infected animal can be the source of infection for eight other animals (2). HEV infection in swine is subclinical and is observed for approximately 10 weeks. Viraemia lasts from 1 to 2 weeks and virus excretion in faeces lasts from 3 to 7 weeks. The virus replicates in the liver, small intestine, large intestine, lymph nodes, and spleen, and is excreted in the bile. The spread of the infection in highly concentrated herds is faster. Apart from pigs, HEV infection can be found in game animals such as wild boars or deer (1). 
Animal studies to identify $\mathrm{HEV}$ infection are undertaken mainly in countries where there are confirmed cases of human hepatitis E (Vietnam, Korea, Taiwan, Brazil, and India), but also in the USA and Europe (23). Studies conducted in Italy, Spain, Hungary, and Germany have demonstrated the presence of this virus in wild boar populations (1). HEV genotype 3 strains are predominant in pigs in Europe $(1,11)$, but infections with genotype 4 are detected in humans and swine in Eastern Asia and Europe. Furthermore, the results of experimental studies indicate that HEV genotypes 3 and 4 can cross the species barrier and so affect humans, swine, rhesus monkeys, and chimpanzees (10).

Although HEV infection in pigs does not pose a major economic risk to pork production, the risk of zoonotic transmission to humans is an important aspect of public health (14). Professionals working in close proximity to swine, swine manure, or sewage, pig farm workers, hunters, and veterinary practitioners may become infected with HEV through occupational activities $(18,24)$. HEV genotype 3 infections have been reported in developed countries in individuals who have consumed raw meat or meat products from deer, wild boars, or pigs (10). In most cases the HEV causes only subclinical infections in humans, but it may cause acute hepatitis $(15,23)$. For this reason, it is essential to monitor the epidemiological situation concerning the occurrence of HEV infections in both livestock and wildlife (1).

The aim of the study was the analysis of the occurrence of specific antibodies against HEV among wild boars and pigs in Poland.

\section{Material and Methods}

In total, 290 serum samples from wild boars and 143 samples from pigs collected in 16 provinces of Poland were tested (Table 1). No ethical or welfare authority approval was required because all the wild boar samples were collected post-mortem by hunters. Porcine samples were collected between 2014 and 2015 during a serological investigation of brucellosis in the Department of Microbiology of the National Veterinary Research Institute in Pulawy, Poland.

The HEV antibodies were tested by ELISA (PrioCHECK HEV Ab porcine, Prionics, Switzerland). Microtitre wells were coated with mixed recombinant antigens of HEV genotypes 1 and 3. Cut-off values were determined for each series of the analysis based on the mean optical density $\left(\mathrm{OD}_{450}\right)$ of the cut-off control. The cut-off was calculated as $\mathrm{OD}_{450}$ of the cutoff control multiplied by 1.2 (cut-off $=1.2 \mathrm{x}_{\text {mean }} \mathrm{OD}_{450}$ of the cut-off control). Values higher than or equal to the cut-off were considered positive, values below the $\mathrm{OD}_{450}$ of the cut-off control were considered negative, and values between the $\mathrm{OD}_{450}$ of the cut-off control and the cut-off were considered borderline. The samples in which the obtained results were borderline were reanalysed and the second value was regarded as final. The test was carried out according to the manufacturer's instructions.

The prevalence of positive, borderline, and negative results was analysed statistically for any difference between pigs and wild boars using Statistica v.10 software (StatSoft, USA). The Chi-square test was performed for nominal features in order to detect statistically significant dependence and the assumed level of significance was $\mathrm{P}=0.05$.

\section{Results}

Positive results of anti-HEV IgG were frequently found in samples collected from pigs (63 samples, $44.1 \%, \mathrm{P}=0.0263$ ) in comparison to samples collected from wild boars (90 samples, 31.0\%). Anti-HEV IgG was detected in $1.4 \%$ samples from pigs and in $2.1 \%$ samples from wild boars at borderline level. A negative result was obtained in $54.5 \%$ of pigs (78 samples) and $66.5 \%$ of wild boars (193 samples). The OD value for anti-HEV IgG observed in animals in Poland is presented in Table 1.

\section{Discussion}

Hepatitis $\mathrm{E}$ is recognised as a zoonotic disease with swine and wild boars being the reservoir for human infections. The increased incidence of hepatitis E cases in Europe is connected with its transmission from wildlife to humans in industrialised countries. Reports on human hepatitis E cases connected with the consumption of undercooked or raw meat have confirmed the hypothesis of zoonotic food-borne HEV infections in humans, as exemplified by Tamada et al. (21) with a report of infection caused by consumption of undercooked liver or meat from domestic pigs or wild boars in Japan.

Natural and experimental HEV infections in swine result in a subclinical infection with severe lesions in the liver and lymph nodes. Seroconversion of HEV antibodies in domestic swine occurs following the typical waning in the maternal antibody levels around 8-10 weeks of age. First, IgM peaks in conjunction with faecal viral shedding, followed by IgG peaking in conjunction with clearance of the virus from the faeces (24).

HEV antibodies have been detected in pigs worldwide with widely variable prevalence. Vasickova et al. (23) reported the prevalence of IgG antibodies to $\mathrm{HEV}$ in serum of domestic pigs in different countries: Great Britain (tested 256, positive 85.5\%), China (tested 419, positive 78.8\%), Brazil (tested 357, positive $63.6 \%$ ), Canada (tested 998, positive 59.5\%), Sweden (tested 204, positive 58\%), Taiwan (tested 274, positive $37.1 \%$ ), the USA (tested 84 , positive $34.5 \%$ ), 
Table 1. The OD value for anti-HEV IgG observed in animals in Poland

\begin{tabular}{|c|c|c|c|c|c|}
\hline Province & Animals & $\begin{array}{c}\text { Number of } \\
\text { animals/positive } \\
\text { results }\end{array}$ & OD average (OD; SD) & $\begin{array}{l}\text { OD } \\
\text { Min }\end{array}$ & $\begin{array}{c}\text { OD } \\
\text { Max }\end{array}$ \\
\hline \multirow{2}{*}{ Lower Silesia } & wild boars & $16 / 3$ & $0.5(0.7 ; 17)$ & 0.1 & 2.8 \\
\hline & pigs & $5 / 3$ & $1.4(1.5 ; 46)$ & 0.2 & 4 \\
\hline \multirow{2}{*}{ Kuyavia-Pomerania } & wild boars & $13 / 3$ & $0.6(0.7 ; 04)$ & 0.1 & 2.2 \\
\hline & pigs & $9 / 4$ & $1.3(1.6 ; 80)$ & 0.2 & 4.3 \\
\hline \multirow{2}{*}{ Lublin } & wild boars & $28 / 14$ & $0.9(0.9 ; 76)$ & 0.1 & 4.3 \\
\hline & pigs & $26 / 18$ & $1.3(0.8 ; 80)$ & 0.2 & 3.0 \\
\hline \multirow{2}{*}{ Lubuskie } & wild boars & $15 / 7$ & $0.8(0.9 ; 23)$ & 0.1 & 3.3 \\
\hline & pigs & $7 / 0$ & $0.3(0.1 ; 23)$ & 0.2 & 0.5 \\
\hline \multirow{2}{*}{ Łódź } & wild boars & $19 / 6$ & $0.7(1.0 ; 88)$ & 0.1 & 3.6 \\
\hline & pigs & $14 / 4$ & $0.9(1.2 ; 27)$ & 0.1 & 4.0 \\
\hline \multirow{2}{*}{ Lesser Poland } & wild boars & $16 / 6$ & $1.0(1.2 ; 45)$ & 0.1 & 4.3 \\
\hline & pigs & $5 / 2$ & $1.2(1.4 ; 08)$ & 0.2 & 3.4 \\
\hline \multirow{2}{*}{ Masovia } & wild boars & $17 / 4$ & $0.5(0.6 ; 55)$ & 0.03 & 2.5 \\
\hline & pigs & $3 / 1$ & $1.2(1.5 ; 94)$ & 0.3 & 3.1 \\
\hline \multirow{2}{*}{ Opole } & wild boars & $16 / 2$ & $0.3(0.3 ; 70)$ & 0.1 & 1.5 \\
\hline & pigs & $7 / 4$ & $1.3(1.0 ; 11)$ & 0.2 & 3.0 \\
\hline \multirow{2}{*}{ Subcarpathia } & wild boars & $19 / 4$ & $0.4(0.3 ; 78)$ & 0.1 & 1.5 \\
\hline & pigs & $11 / 4$ & $0.8(0.6 ; 86)$ & 0.1 & 2.0 \\
\hline \multirow{2}{*}{ Podlasie } & wild boars & $14 / 4$ & $0.6(0.7 ; 39)$ & 0.1 & 2.2 \\
\hline & pigs & $8 / 6$ & $1.4(1.3 ; 69)$ & 0.1 & 4.2 \\
\hline \multirow{2}{*}{ Pomerania } & wild boars & $12 / 3$ & $0.5(0.4 ; 42)$ & 0.1 & 1.3 \\
\hline & pigs & $11 / 4$ & $1.1(1.1 ; 48)$ & 0.1 & 3.3 \\
\hline \multirow{2}{*}{ Silesia } & wild boars & $26 / 6$ & $0.4(0.2 ; 95)$ & 0.1 & 1.1 \\
\hline & pigs & $11 / 4$ & $0.8(0.7 ; 85)$ & 0.2 & 2.2 \\
\hline \multirow{2}{*}{ Holy Cross } & wild boars & $24 / 8$ & $0.7(0.9 ; 85)$ & 0.1 & 4.3 \\
\hline & pigs & $1 / 0$ & $0.2(-)$ & 0.2 & 0.2 \\
\hline \multirow{2}{*}{ Warmia-Masuria } & wild boars & $17 / 6$ & $0.7(1.0 ; 52)$ & 0.1 & 4.3 \\
\hline & pigs & $11 / 3$ & $0.6(0.7 ; 57)$ & 0.1 & 2.5 \\
\hline \multirow{2}{*}{ Greater Poland } & wild boars & $24 / 9$ & $0.8(1.1 ; 68)$ & 0.1 & 4.3 \\
\hline & pigs & $3 / 0$ & $0.3(0.1 ; 51)$ & 0.2 & 0.5 \\
\hline \multirow{2}{*}{ West Pomerania } & wild boars & $14 / 5$ & $1.0(1.3 ; 64)$ & 0.1 & 4.2 \\
\hline & pigs & $11 / 6$ & $1.3(1.1 ; 21)$ & 0.2 & 3.0 \\
\hline
\end{tabular}

Spain (tested 60, positive 25\%), and the Netherlands (tested 34 , positive $23.5 \%$ ). Generally, the prevalence of HEV antibodies in domestic pigs or wild boars is widely variable depending on geographical regions.

In our study, anti-HEV IgG was detected in $44.1 \%$ of samples from 143 pigs tested and in only $31.0 \%$ of samples from 290 wild boars tested. The statistical analysis showed significant differences in these results $(\mathrm{P}=0.0263)$ between the group of pigs and the group of wild boars. It may result from the fact that the serological test used was more specific for swine. The observation indicates that the OD values for anti-HEV $\mathrm{IgG}$ in wild boars were lower than in the examined pigs.

Larska et al. (9) demonstrated that the percentage of seropositive wild boars was $44.4 \%$ and $\mathrm{HEV}$ antibodies were found in the animals from 52 out of 94 hunting sites. Significant variation in the percentages of seropositive wild boars from different provinces was observed. The lowest value (5\%) was recorded for the Holy Cross Province. The highest percentages of seropositive wild boars of $88.2 \%$ and $84.2 \%$ were found in the West Pomerania and Lower Silesia Provinces, respectively. In the study by Larska et al. (9), HEV antibody prevalence in wildlife in Poland was determined in 11 out of 16 provinces of Poland. The samples were collected in 2012-2013 during the classical swine fever monitoring programme. Our study examined wild boars and pigs two years later. The time of sampling or the use of a different test could be the reason for the discordant results obtained by us and by Larska et al. (9). Several studies have investigated the presence of HEV in wild boars in Italy, Germany, the Netherlands, and France (3, 12, 17, 19). In Europe overall, the seroprevalence varies between $12 \%$ in the Netherlands (17) and 61.6\% in Slovenia (7), with Spanish seroprevalence at $47.2 \%$ (5). Studies of wildlife in Poland confirmed that HEV circulates in the wild boar population, which creates a potential risk of virus transmission to domestic animals and humans. Wild boars should be considered an important HEV reservoir with an increasing transmission potential related to their intensively growing population (11).

In the study of Mazzei et al. (12), 64 blood samples were collected from wild boars hunted in central Italy in the 2011-2012 season. Thirty-six (56.2\%) sera were positive for HEV antibodies. The authors confirmed that HEV was endemic in the wild boar population in Italy and these animals could play an important role in the epidemiology of $\mathrm{HEV}$ infection. It was also confirmed that outdoor breeding of autochthonous pigs is increasing in some areas of central Italy and HEV transmission between wildlife and domestic pigs may occur indirectly through water 
and feeding spots contaminated with infected wild boar faeces. It should be emphasised that the vast majority of the pig population in Poland have no direct contact with wildlife. Schlosser et al. (19) proved that HEV in European wild boars is transmissible to domestic pigs horizontally and these animals have to be considered an important HEV reservoir in Europe (19).

Our study was limited by the number of examined samples. The selection of the samples was random with no correspondence to the size of the swine or wild boar population in individual provinces. If the number of examined samples was directly related to the actual population of wild boars or swine in individual provinces, the results would be more representative. All wild boar samples were collected post-mortem by hunters and samples from swine were collected during the serological investigation of brucellosis in the Institute. As a result, it was highly problematic to get sufficient data on the gender or age of all examined animals. Nonetheless, gender has never been associated with the risk of serological positivity. Moreover, HEV was detected in animals from all age groups and seroprevalence did not differ significantly among these groups $(23,24)$.

In conclusion, domestic pigs and wild boars may be a possible source of $\mathrm{HEV}$ infection for humans through direct contact, slaughtering, hunting, or consumption of food of animal origin $(3,4,8)$. Therefore, regular and extensive surveillance of the occurrence of HEV in swine and wild boars should be performed in the future.

Conflict of Interests Statement: The authors declare that there is no conflict of interests regarding the publication of this article.

Financial Disclosure Statement: This study was financed from the internal research funds of Pope John Paul II State School of Higher Education in Biala Podlaska for the project "Assessment of the level of antibodies against HEV in the sera of animals and people at risk of hepatitis E."

Animal Rights Statement: No ethical and welfare authority approval was required because all the wild boar samples were collected post-mortem by hunters.

\section{References}

1. Baumann-Popczyk A.: Hepatitis E as zoonosis. Przegl Epidemiol 2011, 65, 9-13.

2. Bouwknegt M., Engel B., Herremans M.M., Widdowson M.A., Worm H.C., Koopmans M.P., Frankena K., de Roda Husman A.M., De Jong M.C., Van Der Poel W.H.: Bayesian estimation of hepatitis E virus seroprevelance for populations with different exposure levels to swine in the Netherlands. Epidemiol Infect $2008,136,567-576$.

3. Carpentier A., Chaussade H., Rigaud E., Rodriguez J., Berthault C., Boué F., Tognon M., Touzé A., Garcia-Bonnet N., Choutet P., Coursaget P.: High hepatitis E virus seroprevalence in forestry workers and in wild boars in France. J Clin Microbiol 2012, 50, 2888-2893.

4. Colson P., Borentain P., Queyriaux B., Kaba M., Moal V., Gallian P., Heyries L., Raoult D., Gerolami R.: Pig liver sausage as a source of hepatitis E virus transmission to humans. J Infect Dis 2012, 202, 825-834

5. de Deus N., Peralta B., Pina S., Allepuz A., Mateu E., Vidal D., Ruiz-Fons F., Martín M., Gortázar C., Segalés J.: Epidemiological study of hepatitis E virus infection in European wild boars (Sus scrofa) in Spain. Vet Microbiol 2008, 129, 163170 .

6. Herremans M., Vennema H., Bakker J., van der Veer B., Duizer E., Benne C.A., Waar K., Hendrixks B., Schneeberger P., Blaauw G., Kooiman M., Koopmans M.P.: Swine-like hepatitis E viruses are a cause of unexplained hepatitis in the Netherlands. J Viral Hepat 2007, 14, 140-146.

7. Ivanova A., Tefanova V., Reshetnjak I., Kuznetsova T., Geller J., Lundkvist Å., Janson M., Neare K., Velström K., Jokelainen P., Lassen B., Hütt P., Saar T., Viltrop A., Golovljova I.: Hepatitis E virus in domestic pigs, wild boars, pig farm workers, and hunters in Estonia. Food Environ Virol 2015, 7, 403-412.

8. La Rosa G., Muscillo M., Vennarucci V.S., Garbuglia A.R., La Scala P., Capobianchi M.R.: Hepatitis E virus in Italy: molecular analysis of travel-related and autochthonous cases. J Gen Virol 2011, 92, 1617-1626.

9. Larska M., Krzysiak M.K., Jabłoński A., Kęsik J., Bednarski M., Rola J.: Hepatitis E virus antibody prevalence in wildlife in Poland. Zoonoses Public Health 2015, 62, 105-110.

10. Lee G.Y., Poovorawan K., Intharasongkroh D., Sa-Nguanmoo P., Vongpunsawad S., Chirathaworn C., Poovorawan Y.: Hepatitis E virus infection: epidemiology and treatment implications. World J Virol 2015, 4, 343-355.

11. Lewis H. C., Wichmann O., Duizer E.: Transmission routes and risk factors for autochthonous hepatitis $\mathrm{E}$ virus infection in Europe: a systematic review. Epidemiol Infect 2010, 138, 145166.

12. Mazzei M., Nardini R., Verin R., Forzan M., Poli A., Tolari F.: Serologic and molecular survey for hepatitis $\mathrm{E}$ virus in wild boars (Sus scrofa) in Central Italy. New Microbes New Infect 2015, 7, 41-47.

13. Meng X.J., Purcell R.H., Halbur P.G., Lehman J.R., Webb D.M., Tsareva T.S., Haynes J.S., Thacker B.J., Emerson S.U.: A novel virus in swine is closely related to the human hepatitis $\mathrm{E}$ virus. Proc Natl Acad Sci USA 1997, 94, 9860-9865.

14. Miyashita K., Kang J.H., Saga A., Takahashi K., Shimamura T., Yasumoto A., Fukushima H., Sogabe S., Konishi K., Uchida T., Fujinaga A., Matsui T., Sakurai Y., Tsuji K., Maguchi H., Taniguchi M., Abe N., Fazle Akbar S.M., Arai M., Mishiro S.: Three cases of acute or fulminant hepatitis $\mathrm{E}$ caused by ingestion of pork meat and entrails in Hokkaido, Japan: zoonotic food-borne transmission of hepatitis $\mathrm{E}$ virus and public health concerns. Hepatol Res 2012, 42, 870-878.

15. Pavio N., Meng X.J., Renou C.: Zoonotic hepatitis E: animal reservoirs and emerging risks. Vet Res 2010, 41, 46 doi: $10.1051 /$ vetres/2010018.

16. Pérez-Gracia M.T., García M., Suay B., Mateos-Lindemann M.L.: Current knowledge on hepatitis E J Clin Transl Hepatol 2015, 3, 117-126.

17. Rutjes S.A., Bouwknegt M., van der Giessen J.W., de Roda Husman A.M., Reusken C.B.: Seroprevalence of hepatitis E virus in pigs from different farming systems in the Netherlands. J Food Prot 2014, 77, 640-642.

18. Schielke A., Sachs K., Lierz M., Appell B., Jansen A., Johne R.: Detection of hepatitis $\mathrm{E}$ virus in wild boars of rural and urban regions in Germany and whole genome characterization of an endemic strain. Virol J 2009, 6, 58 doi:10.1186/1743-422X-6-58.

19. Schlosser J., Eiden M., Vina-Rodriguez A., Fast C., Dremsek P., Lange E., Ulrich R.G., Groschup M.H.: Natural and experimental hepatitis E virus genotype 3-infection in European wild boar is transmissible to domestic pigs. Vet Res 2014, 45, 121 doi: 10.1186/s13567-014-0121-8. 
20. Smith D.B., Simmonds P., International Committee on Taxonomy of Viruses Hepeviridae Study Group, Jameel S., Emerson S.U., Harrison T.J., Meng X.J., Okamoto H., Van der Poel W.H., Purdy M.A.: Consensus proposals for classification of the family Hepeviridae. J Gen Virol 2014, 95, 2223-2232.

21. Tamada Y., Yano K., Yatsuhashi H., Inoue O., Mawatari F., Ishibashi H.: Consumption of wild boar linked to cases of hepatitis E. J Hepatol 2004, 40, 869-870.
22. Teshale E.H., Hu D.J., Holmberg S.D.: The two faces of hepatitis E virus. Clin Infect Dis 2010, 51, 328-34.

23. Vasickova P., Psikal I., Kralik P., Widen F., Hubalek Z., Pavlik I.: Hepatitis E virus: a review. Vet Med (Praha) 2007, 52, 365-384.

24. Yugo D.M., Meng X.: Hepatitis E Virus: foodborne, waterborne and zoonotic transmission. Int J Environ Res Public Health 2013, $10,4507-4533$. 